\title{
VARIATIONAL FINITE ELEMENT APPROACH TO A HEAT FLOW PROBLEM IN HUMAN LIMBS
}

\author{
V. P. SAXENA and M. P. GUPTA \\ School of Mathematics and Allied Sciences \\ Jiwaji University \\ Gwalior, India \\ (Received November 14, 1990 and in revised form March 10, 1991)
}

\begin{abstract}
An attempt has been made to study cross sectional temperature distribution in in-vivo tissues of a human limb employing variational finite element approach. The outermost surface of the limb is assumed to be exposed to the atmosphere. The physiological and physical parameters like rate of metabolic heat generation ( $\mathrm{rmhg}$ ), blood mass flow rate (bmfr) and thermal conductivity are assumed to vary in the subregions independently. Numerical results have been obtained for various cases of practical interest.
\end{abstract}

KEY WORDS AND PHRASES: Metabolic heat generation; blood mass flow; thermal conductivity; finite element method.

1991 AMS SUBJECT CLASSIFICATION CODES. $76 \mathrm{Z}$

\section{INTRODUCTION.}

The temperature distribution in the peripheral region of limbs of a human body undergo frequent changes on account of changes in atmospheric temperature, the core being maintained at a nearly uniform temperature. The peripheral region comprises of non-uniform layers and has variable blood flow, metabolic heat generation and allied process. This intermediatory region play a very important role in maintaining a balance between the atmospheric variations and the interior consisting of intra-abdominal, intrathoracic and intracranial regions. Usually rectal and oesophageal temperatures are taken to represent core temperature. Oesophageal temperature taken at heart level is a good index of rapid changes of cardiac and aortic blood temperature. The temperature of the limbs and the surface layer of the trunk exhibits a wide variation of temperature.

This paper employs a variational finite element approach to study the temperature distribution in a normal cross-sectional region of a limb. Due to unsymmetric situations of large blood vessels passing through the core of the limb the inter-face has angular variation. The peripheral part of limb is directly exposed to atmosphere.

The peripheral part, assumed to be annular in geometry, has been approximated by the assembly of triangular elements of different sizes. Thus the circular boundaries are approximated by the polygonal one's. Different types of variations of parameters have been considered for different natural subregions such as stratum corneum, stratum germinitivum, dermis and underlying tissue (Montagana [1], Jarrett [2] and Gray [3]). Finite element formulation provides necessary flexibility in taking care of different behavior of distinctly different subregions. 


\section{MATHEMATICAL MODEL.}

The rate of change of temperature $u$ at a point in in vivo tissue at time $t$ is given by the following partial differential equation (Perl [4])

$$
e \bar{c} \frac{\partial u}{\partial t}=\operatorname{div}[K \operatorname{grad} u]+m_{b} c_{b}\left(u_{A}-u\right)+S
$$

where $e, \bar{c}$ and $K$ are respectively density, specific heat and thermal conductivity of the tissue; $m_{b}$ and $c_{b}$ are blood mass flow rate and specific heat of the blood respectively; $S$ is the rate of metabolic heat generation per unit volume and $u_{A}$ is the arterial blood temperature. Above equation has been modified and extensively used by Saxena [5], Saxena and Arya [6], Saxena and Bindra [7,8] in the thermal study of human skin and subcutaneous tissue. Here we employ the same for a human limb with circular symmetry.

The surface of the limb is assumed to be exposed to the atmosphere at temperature $u_{a}$. The heat transfer coefficient between skin and the atmosphere may be due to convection, radiation and evaporation. Hence the boundary condition at skin surface can be put as

$$
-K \frac{\partial u}{\partial n}=h\left(u-u_{a}\right)+L E
$$

where $n$ is the direction of the normal, $h$ is coefficient of convection, $L$ is the latent heat of evaporation, $E$ is the rate of sweat evaporation. At the inner boundary we put

$$
\begin{array}{c|c}
u(x, y)=f(x, y) \mid \begin{array}{c}
(10 d \leq x \leq 18 d) \\
(0 \leq y \leq 4 d)
\end{array} \\
\frac{\partial u}{\partial y}=0 \quad \begin{array}{c}
(0 \leq x \leq 10 d) \\
(18 d \leq x \leq 28 d)
\end{array}
\end{array}
$$

where $d$ is a distance constant. The boundary condition (2.4) corresponds to the case of mirror symmetry in temperature distribution about $x$-axis (horizontal diameter). The variational form of equation (2.1) for a two dimensional steady state case along with the boundary condition (2.2) is given by (Myers [9])

$$
I=\frac{1}{2} \iint_{\lambda}\left[K\left(\frac{\partial u}{\partial x}\right)^{2}+K\left(\frac{\partial u}{\partial y}\right)^{2}+m_{b} c_{b}\left(u_{A}-u\right)^{2}-2 S u\right] d x d y+\int_{b}\left[h\left(u-u_{a}\right)^{2}+2 L E u\right] d \Omega
$$

Here the problem region $A$ with boundary $\Omega$ is a cylindrical limb with circular cross-sectional and symmetrical with respect to $x$-axis. The region of interest is semi-circular and is descretized into 150 triangular elements and 96 nodes as shown in Fig. 1. Here the angular points of each element are the nodal points.

The integral in equation (2.5) may be written as

$$
I=I_{k}+I_{m}+I_{s}+I_{\Omega}
$$

where

$$
\begin{gathered}
m=m_{b} c_{b} \\
I_{k}=\frac{1}{2} \iint_{A} K\left[\left(\frac{\partial u}{\partial x}\right)^{2}+\left(\frac{\partial u}{\partial y}\right)^{2}\right] d x d y \\
I_{m}=\frac{1}{2} \iint_{A} m\left(u_{A}-u\right)^{2} d x d y
\end{gathered}
$$




$$
\begin{gathered}
I_{s}=-\iint_{\lambda} S u d x d y \\
I_{\Omega}=\frac{1}{2} \int_{h}\left[h\left(u-u_{a}\right)^{2}+2 L E u\right] d \Omega
\end{gathered}
$$

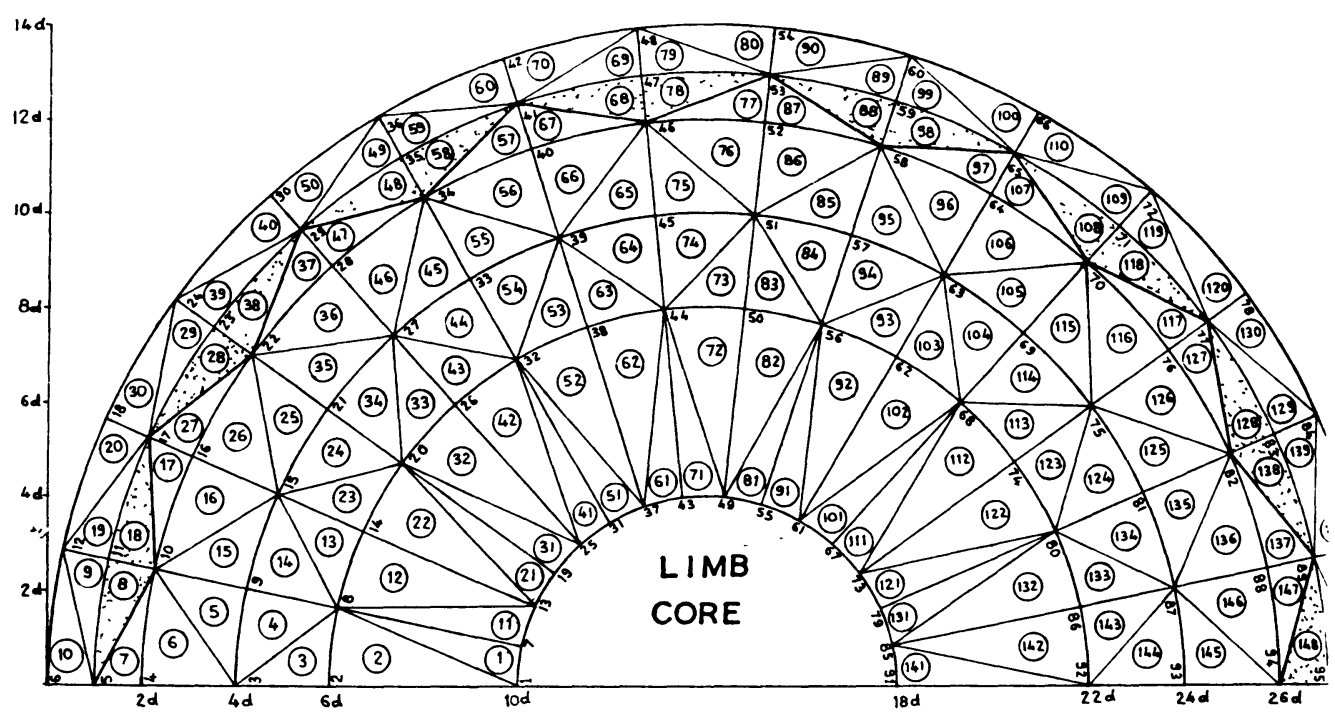

Fig. 1. Triangular Element Arrangement for Annular Cross Section of Human Limbs Numerals Without Circles Nodes and with Circles Denote Element Numbers

Next we extremize $I$ by differentiating it with respect to each nodal temperature $u_{i}$ and setting derivatives equal to zero. That is

$$
\frac{d I}{d U}=\frac{d I_{r}}{d U}=0, \quad r=k, m, s, \Omega
$$

where 


$$
U=\left[\begin{array}{c}
u_{1} \\
\cdot \\
\cdot \\
\cdot \\
u_{t} \\
u_{j} \\
u_{k} \\
\cdot \\
\cdot \\
\cdot \\
u_{96}
\end{array}\right]
$$

In view of the biology the region under study has been divided into one hundred and fifty triangular elements so that the integrals in equation (2.11) are computed as a sum over each of the elements. Hence

$$
\frac{d I_{r}}{d U}=\sum_{e=1}^{150} \frac{d I_{r}^{(e)}}{d U}, \quad r=k, m, s, \Omega .
$$

Here (e) stands for the elements whose nodes are $i, j$ and $k$. The expression on the right-hand side of equation (2.13) for $r=\Omega$ will be summed up for the elements on the boundary of the outer surface of the limb. Equations (2.13) will be commuted separately and then substituted into equation (2.11). For the (e)th element $u_{i}, u_{j}$ and $u_{k}$ are the only temperatures to be taken into account. For this element $I_{k}^{(e)}, I_{m}^{(e)}$ and $I_{s}^{(c)}$ will be function of these three corner temperatures only. Whereas $I_{\Omega}^{(c)}$ will be function of only two corner temperatures which lie on the outer boundary and element $(e)$ adjoining this boundary. Consequently, the partial derivatives of $I_{r}^{(e)}$ for $r=k, m, s$, with respect to all other nodal temperatures will be zero.

\section{SOLUTION.}

The following linear variation of temperature within each element is expressed as

$$
u^{(e)}=p^{T} C^{(e)}
$$

where

$$
p^{T}=[1, x, y], \quad C^{(e)}=\left[\begin{array}{c}
c_{1}^{(e)} \\
c_{2}^{(e)} \\
c_{3}^{(e)}
\end{array}\right]
$$

Now $u^{(e)}$ is equal to $u_{i}, u_{j}$ and $u_{k}$ at the corners of the $e$ th element whose nodal temperatures are $u_{i}, u_{j}$ and $u_{k}$. Thus we have

$$
U^{(e)}=p^{(e)} C^{(e)}
$$

where

$$
U^{(e)}=\left[\begin{array}{l}
u_{j} \\
u_{j} \\
u_{k}
\end{array}\right], \quad p^{(e)}=\left[\begin{array}{lll}
1 & x_{i} & y_{i} \\
1 & x_{j} & y_{j} \\
1 & x_{k} & y_{k}
\end{array}\right]
$$

Now solving equation (3.2) for $C^{(e)}$ as given below

$$
C^{(e)}=R^{(e)} U^{(e)}
$$

where

$$
R^{(e)}=p^{(e)^{-1}}
$$


Substituting the value of $C^{(e)}$ from equation (3.3) in equation (3.1) we obtain

$$
u^{(e)}=p^{T} R^{(e)} U^{(e)}
$$

With the help of equation (3.4), we can evaluate the integral $I$. Further differentiating $I$ with respect to each nodal temperatures and setting derivatives equal to zero we arrive at the following system of simultaneous equations

$$
W U=Z
$$

where $W$ is a matrix of order $(96 \times 96)$ and $Z$ is a matrix of order $(96 \times 1)$. Finally solving the system of simultaneous equations (3.5) we obtain the values of nodal temperatures (see Table I).

\section{NUMERICAL RESULTS}

Assumptions regarding thermal conductivity, metabolic heat generation and blood mass flow rate are given as under (Knudsen and Overgaard [10], Saxena and Bindra [7,8]).

\begin{tabular}{|cccc|}
\hline $\begin{array}{c}\text { For the } \\
\text { Elements of } \\
\text { Subregions }\end{array}$ & $\begin{array}{c}K^{(e)} \mathrm{cal} / \\
\mathrm{cm}-\mathrm{min}-\mathrm{degc}\end{array}$ & $S^{(e)}$ & $M^{(e)}$ \\
\hline Ist & 0.060 & $S_{\max }=s$ & $M_{\max }=m$ \\
IInd & 0.050 & $7 / 8 s$ & $2 / 3 m$ \\
IIIrd & 0.040 & $5 / 8 s$ & $1 / 3 m$ \\
IVth & 0.035 & $3 / 8 s$ & $1 / 6 m$ \\
Vth & 0.030 & $1 / 8 s$ & 0.0 \\
VIth & 0.030 & 0.0 & 0.0 \\
\hline
\end{tabular}

The numerical results have been computed for two different cases of atmospheric temperatures as given below

\begin{tabular}{|l|c|c|}
\hline & Case-I & Case-II \\
\cline { 2 - 3 } & $u_{a}=15^{\circ} \mathrm{C}$ & $u_{a}=23^{\circ} \mathrm{C}$ \\
\hline$m$ cal./cm ${ }^{3}$-min.-deg $C$ & 0.003 & 0.018 \\
$s$ cal. $/ \mathrm{cm}^{3}$-min. & 0.0357 & 0.018 \\
$E$ gm $/ \mathrm{cm}^{3}$-min. & 0.0 & $0.12 \times 10^{-3}$ \\
& & $0.24 \times 10^{-3}$ \\
\hline
\end{tabular}

$L=579 \mathrm{cal} / \mathrm{gm}, \boldsymbol{h}=0.009 \mathrm{cal} / \mathrm{cm}$-min-deg. $C$.

The constant ' $d$ ' can be assigned any value depending on the sample of the limb under study. Here we have taken

$$
d=0.625 \mathrm{~cm}
$$

The values of nodal temperatures have been obtained for two cases of atmospheric temperatures and are given in Table I. The temperatures at the nodes with numbers 1,7,13,19,25,31,37,43,49,55,67,73,79,85 and 91 (along the inner boundary) reflect the variation in the limb core temperature with respect to position. 
The effect of this variation in limb core temperature on the other subregions is visible in Table I. On comparing the nodal temperature on outer surface and in each subregion, it is observed that these nodal temperatures vary considerably with the change in atmospheric temperatures and rate of sweat evaporation.

The finite element method used here has made it possible to include more details of biology such as the wavy structure of the layers and different values of physical and physiological parameters in each subregion. A computer program was developed and executed on ICIM 6040 to perform these computations.

\begin{tabular}{|c|c|c|c|}
\hline \multirow{2}{*}{$\begin{array}{c}\text { Nodal } \\
\text { Temperatures }\end{array}$} & \multirow{2}{*}{$\begin{array}{c}u_{a}=15^{\circ} \mathrm{C} \\
E=0\end{array}$} & \multicolumn{2}{|c|}{$u_{a}=23^{\circ} \mathrm{C}$} \\
\hline & & $E=0.12 \times 10^{-3} \Omega$ & $E=0.24 \times 10^{-3} \Omega$ \\
\hline $\mathrm{u} 1$ & 30.00 & 30.00 & 30.00 \\
\hline u2 & 29.51 & 29.91 & 29.22 \\
\hline u3 & 29.06 & 28.85 & 27.56 \\
\hline u4 & 26.63 & 26.65 & 24.27 \\
\hline u5 & 25.14 & 25.21 & 22.14 \\
\hline u6 & 23.49 & 23.60 & 19.77 \\
\hline $\mathrm{u} 7$ & 30.26 & 30.26 & 30.26 \\
\hline u8 & 29.82 & 30.01 & 29.32 \\
\hline u9 & 29.02 & 28.84 & 27.51 \\
\hline u10 & 26.74 & 26.78 & 24.43 \\
\hline u11 & 25.08 & 25.16 & 22.04 \\
\hline u12 & 23.42 & 23.53 & 19.65 \\
\hline u13 & 30.53 & 30.53 & 30.53 \\
\hline u14 & 30.47 & 30.12 & 29.42 \\
\hline u15 & 29.18 & 29.05 & 27.76 \\
\hline u16 & 26.69 & 26.78 & 24.38 \\
\hline u17 & 25.21 & 25.34 & 22.26 \\
\hline u18 & 23.57 & 23.73 & 19.91 \\
\hline u19 & 30.80 & 30.80 & 30.80 \\
\hline u20 & 30.68 & 30.36 & 29.68 \\
\hline u21 & 29.24 & 29.16 & 27.83 \\
\hline u22 & 26.89 & 27.03 & 24.68 \\
\hline u23 & 25.19 & 25.35 & 22.22 \\
\hline u24 & 23.54 & 23.72 & 19.84 \\
\hline u25 & 31.06 & 31.06 & 31.06 \\
\hline u26 & 30.79 & 30.54 & 29.84 \\
\hline u27 & 29.44 & 29.43 & 28.14 \\
\hline u28 & 26.89 & 27.08 & 24.68 \\
\hline u29 & 25.40 & 25.62 & 22.55 \\
\hline u30 & 23.70 & 23.93 & 20.09 \\
\hline u31 & 31.33 & 31.33 & 31.33 \\
\hline u32 & 31.03 & 30.81 & 30.13 \\
\hline
\end{tabular}




\begin{tabular}{|c|c|c|c|}
\hline \multirow{2}{*}{$\begin{array}{c}\text { Nodal } \\
\text { Temperatures }\end{array}$} & \multirow{2}{*}{$\begin{array}{c}u_{a}=15^{\circ} \mathrm{C} \\
E=0\end{array}$} & \multicolumn{2}{|c|}{$u_{a}=23^{\circ} \mathrm{C}$} \\
\hline & & $E=0.12 \times 10^{-3} \Omega$ & $E=0.24 \times 10^{-3} \Omega$ \\
\hline u33 & 29.51 & 29.55 & 28.21 \\
\hline u34 & 27.13 & 27.38 & 25.03 \\
\hline u35 & 25.39 & 25.64 & 22.51 \\
\hline u36 & 23.70 & 23.95 & 20.08 \\
\hline u37 & 31.60 & 31.60 & 31.60 \\
\hline u38 & 31.16 & 31.00 & 30.31 \\
\hline u39 & 29.76 & 29.86 & 28.56 \\
\hline$u 40$ & 27.15 & 27.45 & 25.06 \\
\hline$u 41$ & 25.59 & 25.90 & 22.83 \\
\hline$u 42$ & 23.88 & 24.19 & 20.36 \\
\hline$u 43$ & 31.86 & 31.86 & 31.86 \\
\hline$u 44$ & 31.43 & 31.30 & 30.63 \\
\hline$u 45$ & 29.84 & 29.90 & 28.66 \\
\hline$u 46$ & 27.38 & 27.73 & 25.37 \\
\hline$u 47$ & 25.65 & 25.99 & 22.88 \\
\hline$u 48$ & 23.88 & 24.21 & 20.34 \\
\hline$u 49$ & 32.13 & 32.13 & 32.13 \\
\hline u50 & 31.55 & 31.48 & 30.79 \\
\hline u51 & 30.07 & 30.28 & 28.98 \\
\hline u52 & 27.41 & 27.81 & 25.41 \\
\hline u53 & 25.80 & 26.20 & 23.11 \\
\hline u54 & 24.07 & 24.46 & 20.63 \\
\hline u55 & 32.40 & 32.40 & 32.40 \\
\hline u56 & 31.79 & 31.76 & 31.08 \\
\hline u57 & 30.17 & 30.41 & 29.08 \\
\hline u58 & 27.65 & 28.10 & 25.74 \\
\hline u59 & 25.87 & 26.29 & 23.18 \\
\hline u60 & 24.07 & 24.46 & 20.59 \\
\hline u61 & 32.66 & 32.66 & 32.66 \\
\hline u62 & 31.92 & 31.94 & 31.25 \\
\hline u63 & 30.41 & 30.73 & 29.43 \\
\hline u64 & 27.68 & 28.17 & 25.78 \\
\hline u65 & 26.07 & 26.55 & 23.49 \\
\hline u66 & 24.26 & 24.71 & 20.89 \\
\hline u67 & 32.93 & 32.93 & 32.93 \\
\hline u68 & 32.16 & 32.22 & 31.54 \\
\hline u69 & 30.47 & 30.83 & 29.50 \\
\hline u70 & 27.93 & 28.47 & 26.13 \\
\hline u71 & 26.04 & 26.54 & 23.40 \\
\hline u72 & 24.23 & 24.70 & 20.81 \\
\hline u73 & 33.20 & 33.20 & 33.20 \\
\hline u74 & 32.26 & 32.38 & 31.69 \\
\hline
\end{tabular}




\begin{tabular}{|c|c|c|c|}
\hline \multirow{2}{*}{ Nodal } & $u_{a}=15^{\circ} \mathrm{C}$ & \multicolumn{2}{|c|}{$u_{a}=23^{\circ} \mathrm{C}$} \\
\cline { 2 - 4 } Temperatures & $E=0$ & $E=0.12 \times 10^{-3} \Omega$ & $E=0.24 \times 10^{-3} \Omega$ \\
\hline u75 & 30.67 & 31.11 & 29.80 \\
u76 & 27.89 & 28.49 & 26.09 \\
u77 & 26.31 & 26.88 & 23.83 \\
u78 & 24.38 & 24.90 & 21.06 \\
u79 & 33.46 & 33.46 & 33.46 \\
u80 & 32.48 & 32.64 & 31.96 \\
u81 & 30.73 & 31.20 & 29.86 \\
u82 & 28.12 & 28.77 & 26.43 \\
u83 & 26.18 & 26.77 & 23.62 \\
u84 & 24.39 & 24.93 & 21.06 \\
u85 & 33.73 & 33.73 & 33.73 \\
u86 & 32.52 & 32.73 & 32.04 \\
u87 & 30.88 & 31.42 & 30.12 \\
u88 & 28.07 & 28.77 & 26.38 \\
u89 & 26.38 & 27.04 & 23.96 \\
u90 & 24.54 & 25.14 & 21.31 \\
u91 & 34.00 & 34.00 & 34.00 \\
u92 & 32.64 & 32.87 & 32.19 \\
u93 & 30.85 & 31.38 & 30.05 \\
u94 & 28.22 & 28.94 & 26.59 \\
u95 & 26.29 & 26.94 & 23.81 \\
u96 & 24.46 & 25.05 & 21.18 \\
\hline
\end{tabular}

where $\Omega=g m / \mathrm{cm}^{3}-\min$

\section{REFERENCES}

1. MONTAGNA, W. The Structure and Function of Skin, Academic Press (1962).

2. JARRETT, A. The Physiology and Pathophysiology of Skin, Academic Press (1973).

3. GRAY, H. Text Book of Gray's Anatomy, Longmans Press (1973).

4. PERL, W. Heat and Matter Distribution in Body Tissues and Determination of Tissue Blood Flow by Local Clearance Method, J. Theo. Biol. 2 (1962), 201-235.

5. SAXENA, V. P. Temperature Distribution in Human Skin and Subdermal Tissues, $\underline{\mathbf{J}}$. Theo. Biol. 102 (1983), 277-286.

6. SAXENA, V. P. and ARYA, D. Exact Solution of the Temperature Distribution Problem in Epidermis and Dermis Regions of Human Body, Proc. VNM. Medical and Biological Engineering, Sweden (1981), 364-366.

7. SAXENA, V. P. and BINDRA. J. S. Steady State Temperature Distribution in Dermal Regions of Human Body with Variable Blood Flow, Perspiration and Self-Controlled Metabolic Heat Generation, J. Pure Appl. Math. 15(1) (1984), 31-42.

8. SAXENA, V. P. and BINDRA, J. S. Quadratic Shape Functions in Variational Finite Element Approach to Heat Distribution in Cutaneous and Subcutaneous Tissues, Ind. J. Pure Appl. Math. 18(9) (1987), 846-855.

9. MYERS, G. E. Analytical Methods in Conduction Heat Transfer, McGraw Hill (1971).

10. KNUDSEN, M. and OVERGAARD, J. Identification of Thermal Model for Human Tissue, IEEE Trans. Biomed. Eng. BME-33 (1986), 477-485. 


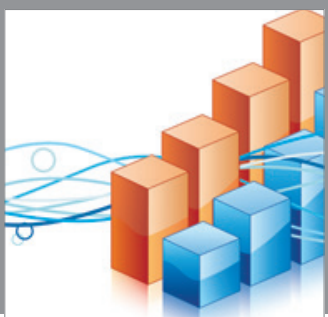

Advances in

Operations Research

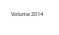

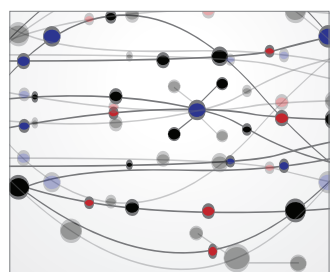

\section{The Scientific} World Journal
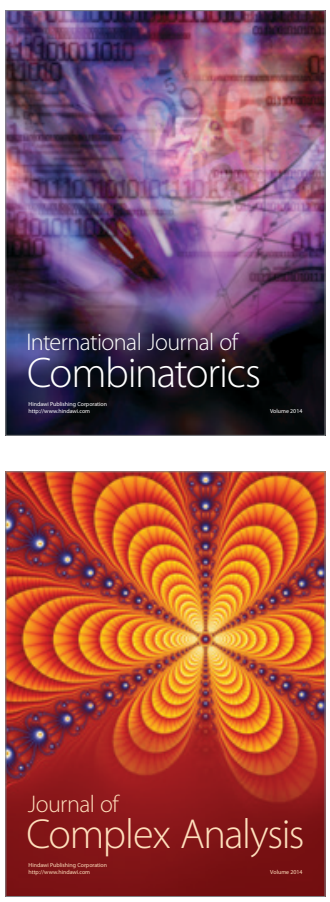

International Journal of

Mathematics and

Mathematical

Sciences
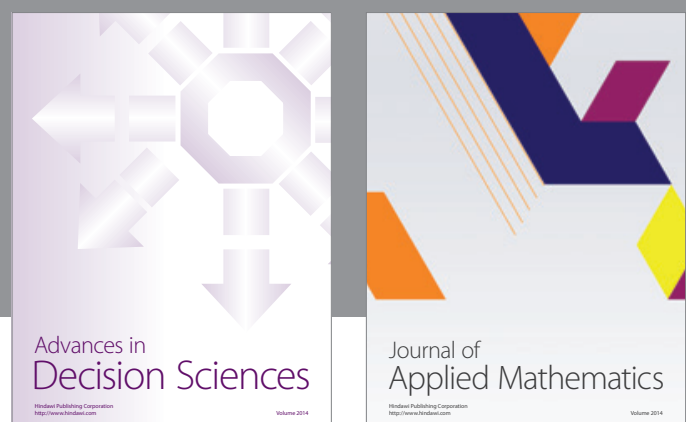

Journal of

Applied Mathematics
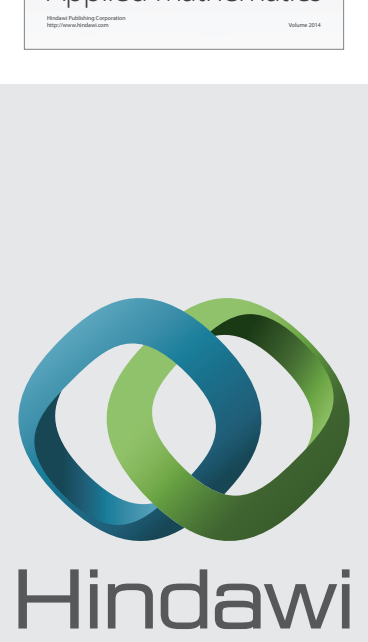

Submit your manuscripts at http://www.hindawi.com
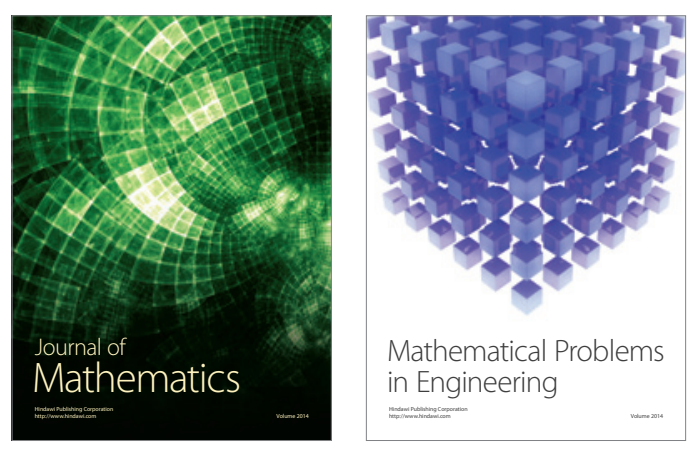

Mathematical Problems in Engineering
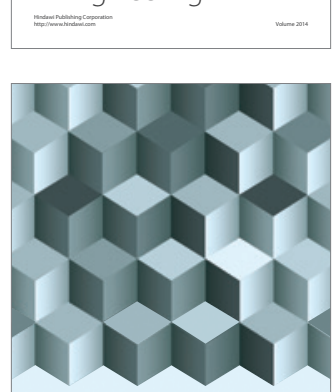

Journal of

Function Spaces
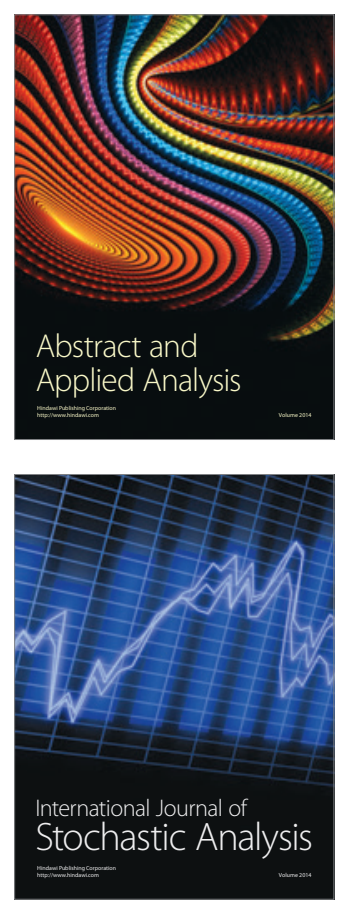

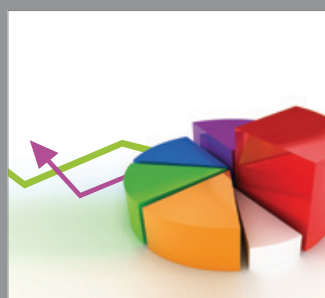

ournal of

Probability and Statistics

Promensencen
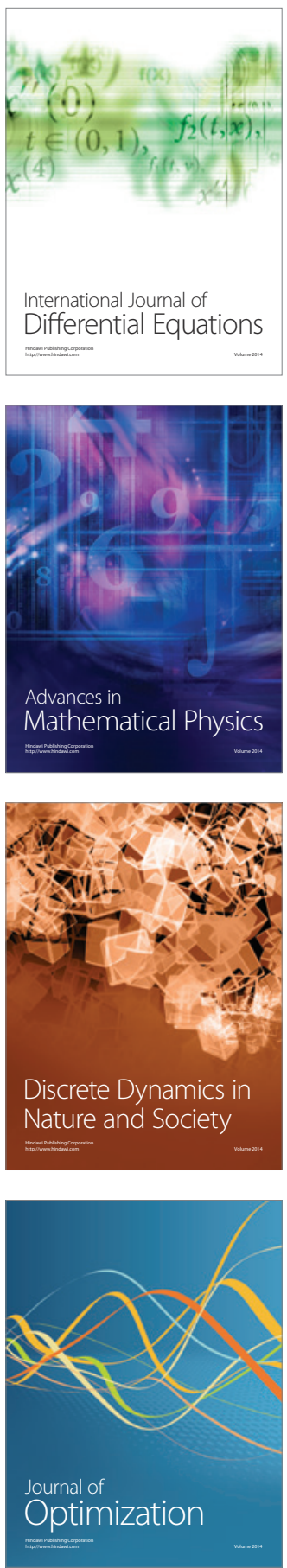